\title{
The best treatment for the first episode of primary spontaneous pneumothorax: an unanswered question
}

\section{To the Editor:}

I read with great interest the study by TsCHOPP et al. [1]. They compared in a multicentre randomised study two groups of patients with primary spontaneous pneumothorax (PSP), in order to study the recurrence rate, the side-effects (mainly the pain) and the cost of two treatment modalities, thoracoscopic talcage (TT) or pleural drainage (PD). They found that, after 5 yrs of follow-up, 34\% of PSP patients treated with PD relapsed, versus 5\% in the TT group, and that TT is a safe, cost-effective treatment with less morbidity provided there is an efficient control of pain by opioids.

I expected to find an answer to a recurrent and essential question in this manuscript: "do we have to propose TT or simple PD for the first episode of PSP if aspiration has failed?" Unfortunately, this was not the case. Indeed, the authors decided to include all the patients with PSP, whether they presented with a first or a recurrent episode of PSP. As shown in table 2, only 23 and $36 \%$ of the patients treated with TT and PD respectively, had a first episode of PSP. We all know, as the authors quoted in their introduction, that there is a "general consensus that some treatment is mandatory with second or recurrent SP". In other words, a TT is advised from the first recurrence. Scarce scientific data, but above all, clinical experience suggests that after a first recurrence of PSP, the incidence of subsequent recurrences increases progressively over time, up to $62 \%$ for a second and $83 \%$ for a third recurrence [2]. To show that TT as compared to PD is a costeffective treatment for a majority of patients with recurrent PSP, brings no major information. A subanalysis of the "true" patients (with first episode of PSP) would have given more power to this study.

Another study should be reproduced eventually using patients with a first episode of PSP. It should offer relevant answers in our current practice, and will complete the data of a nonrandomised and nonprospective study performed by SCHRAMEL et al. [3] that was published in the European Respiratory Journal in 1996. These authors also examined the cost-effectiveness of PD versus TT for PSP in two successive periods. TT was not cheaper than PD except if the costs of the waiting times before TT were subtracted. All kinds of PSP were included. One-third of the patients presented with a recurrent PSP. Guidelines for the treatment of first episode of PSP cannot be easily drawn from these results. Interestingly, only $27 \%$ of the patients treated with PD relapsed after a follow-up of $8 \mathrm{yrs}$, and $19 \%$ after $1 \mathrm{yr}$.

Nevertheless, if such a study is ever considered, some modifications should be introduced in the methodology. I think that a pleural suction should be used in the same way in the pleural drainage group as in the thoracoscopic talcage group. First, TschOpp et al. [1] decided to use suction after $12 \mathrm{~h}$ in the pleural drainage group if the lung failed to reexpand, and immediately in the thoracoscopic talcage group. Secondly, in the thoracoscopic talcage group, why should suction be sustained for $\geqslant 2$ days "or" until air leakage has stopped? It should perhaps be better to write "and until the suction has stopped" or "suction was maintained $24 \mathrm{~h}$ or $48 \mathrm{~h}$ after air leakage has stopped". Thirdly, a true comparison of the costs between the two methods in general and, centre by centre in the case of a new multicentre study, should be carried out. An independent reader cannot react otherwise than with greatest precaution when the results about costs in this prospective study concerned only one-third of the population even if the cases were randomly selected. Finally, is there any good reason after thoracoscopic procedure to insert a drain through another hole, i.e. the sixth intercostal space in the midaxillary line, when the thoracoscope was previously inserted in the fourth or fifth intercostal space on the same line?

\section{T. Pieters}

Pneumology unit, Cliniques Universitaires Saint-Luc, Université Catholique de Louvain, Brussels, Belgium.

\section{References}

1. Tschopp JM, Boutin C, Astoul P, et al. Talcage by medical thoracoscopy for primary spontaneous penumothorax is more cost-effective than drainage: a randomised study. Eur Respir J 2002; 20: 1003-1009.

2. Light RW. Pleural Diseases. 4th Edn. Philadelphia, Lippincott Williams and Wilkins, 2001; pp. 284-319.

3. Schramel FMNH, Sutedja TG, Braber JCE, van Mourik JC, Postmus PE. Cost-effectiveness of video-assisted thoracoscopic surgery versus conservative treatment for first time or recurrent spontaneous pneumothorax. Eur Respir J 1996; 9: $1821-1825$.

\section{From the authors:}

We would like to thank T. Pieters for his interest in our paper and take the occasion to reply to some of his questions. First, should thoracoscopic talc (TT) poudrage be proposed for the management of a first episode of primary spontaneous pneumothorax (PSP) if a simple treatment such as aspiration has failed? In our study we included all patients with PSP requiring chest-tube drainage. A subanalysis of the 28 patients who presented with a first episode of PSP would most likely show the same results, as there was no difference in any clinical characteristics between a first episode and recurrent PSP. However, it is a good question which might be answered in another study including only patients with a first episode of PSP. We definitely showed in a prospective way, that simple thoracoscopic talc poudrage under local anaesthesia is a safe (there were no complications at all) and costeffective treatment of PSP requiring chest-tube drainage. Moreover, because of the design of the study, we did not take into account the costs of rehospitalisation for a late recurrence which were, as expected, much higher in the conservative group treated by chest tube alone. This would 
certainly have corroborated the findings that TT poudrage is more cost-effective than chest-tube drainage, a well accepted treatment for PSP requiring a chest tube. In other words, our study, performed with a randomised, prospective design, definitely showed that TT poudrage is superior to conservative treatment by chest-tube drainage. This is important information which has never been reported before. SCHRAMEL et al. [1] performed a different study. They compared retrospectively, in two historical series, video-assisted thoracoscopic surgery (VATS) under general anaesthesia to chest-tube drainage alone, as treatment of PSP requiring chest-tube drainage. They showed that the more expensive technique, VATS, was more cost-effective than conservative treatment. The same authors further concluded that using simple talc poudrage would have resulted in an additional $62 \%$ reduction of the cost [2]. A mini-invasive technique, such as thoracoscopy with talc pleurodesis, is very effective in preventing recurrence of a spontaneous pneumothorax either for a first episode of PSP or secondary pneumothorax, even it is an old technique performed for a $100 \mathrm{yrs}$, as suggested by WEISSBERG and REFAELY [3]. We think that in today's standard of care, the patient with a first episode of PSP requiring a chest tube should be offered the choice between a treatment which importantly reduces the recurrence rate (TT), versus a treatment with a higher recurrence rate (pleural drainage), both treatments implying the same duration of hospital stay.

Secondly, we agree that there is ongoing discussion about when and how long to apply suction through the chest tube in either group. Unfortunately, there is currently no answer to this question because of lack of scientific data. We decided to use suction immediately in the TT group because it is performed in this way in all centres participating in the study, based on the idea that the sooner parietal and visceral pleural are brought in contact with each other, the better.

Thirdly, we do not agree with the comment about the method of cost calculation as proposed. Our study was a multicentre European trial conducted in five countries with different health systems and different hospital reimbursement policies. The only economically reliable method to look at the real costs was to unify the method of calculation, after having meticulously recorded all procedures material and manpower used for each patient.

Finally, although it is very easy to insert a second drain under visual control at the end of thoracoscopy, we agree that the same hole can be used for this purpose.

J-M. Tschopp*, C. Boutin ${ }^{\#}$, P. Astoul ${ }^{\#}$, J-P. Janssen ", C-T. Bolliger ${ }^{+}$, L. Delaunois ${ }^{\S}$, P. Driesen ${ }^{f}$, G. Tassi**, A-P. Perruchoud and the European Study on Medical Video-Assisted Thoracoscopy (ESMEVAT) team

*Centre Valaisan de Pneumologie, Montana, Switzerland. ${ }^{\text {\#}}$ Service de Pneumologie, Hôpital de la Conception, Marseille, France. "Afdeling Longziekten, Canisius Wilhelmina Ziekenhuis, Nijmegen, the Netherlands. ${ }^{+}$Abteilung für Pneumologie, Universitätskantonsspital, Basel, Switzerland. ${ }^{\$}$ Service de Pneumologie, Cliniques Universitaires UCL de Mont-Godinne, Yvoir, Belgium. ${ }^{f}$ St Elisabeth $\mathrm{ZH}$, Turnhout, Belgium. **Divisione di Pneumologia, Spedali Civili, Brescia, Italy.

\section{References}

1. Schramel FMNH, Sutedja TG, Braber JCE, van Mourik JC, Postmus PE. Cost-effectiveness of video-assisted thoracoscopic surgery versus conservative treatment for first time or recurrent spontaneous pneumothorax. Eur Respir J 1996; 9: $1821-1825$

2. Noppen N. Treatment of spontaneous pneumothorax - an ongoing debate. Eur Respir J 1998; 11: 514-515.

3. Weissberg D, Refaely Y. Pneumothorax: experience with 1,199 patients. Chest 2000; 117: 1279-1285.

\section{Carbon dioxide production during acetazolamide and medroxyprogesterone treatment}

\section{To the Editor:}

WAGENAAR et al. [1] report improvement in gas exchange and increased minute ventilation $\left(V^{\prime} \mathrm{E}\right)$ in patients with stable, moderately severe chronic obstructive pulmonary disease receiving treatment with acetazolamide and medroxyprogesterone. They estimate a baseline carbon dioxide $\left(\mathrm{CO}_{2}\right)$ production rate of $400 \mathrm{~mL} \cdot \mathrm{min}^{-1}$ from the placebo values for $\mathrm{CO}_{2}$ arterial tension $\left(\mathrm{Pa}_{1} \mathrm{CO}_{2}\right)$ of $6.5 \mathrm{kPa}$ or $49 \mathrm{mmHg}$ and $V^{\prime} \mathrm{E}$ of $9.3 \mathrm{~L} \mathrm{~min}^{-1}$. Assuming that $\mathrm{Pa}, \mathrm{CO}_{2}$ can be substituted for alveolar carbon dioxide tension $\left(\mathrm{PCO}_{2}\right)$, one can calculate the dead space to tidal volume ratio ( $V \mathrm{D}: V \mathrm{~T})$ using the standard formula [2]:

$$
P_{\mathrm{a}, \mathrm{CO}_{2}}=0.863 \frac{V^{\prime} \mathrm{CO}_{2}}{V^{\prime} \mathrm{E}\left(1-\frac{V_{\mathrm{D}}}{V_{\mathrm{T}}}\right)}
$$

where $V^{\prime} \mathrm{CO}_{2}$ is carbon dioxide production.

The $V \mathrm{D}: V \mathrm{~T}$ calculates to 0.24 , a surprisingly low value in patients with advanced airways obstruction. If this value is modified by the increased $V \mathrm{~T}$ during acetazolamide and medroxyprogesterone treatment and one calculates $V^{\prime} \mathrm{CO}_{2}$ $\left(P \mathrm{a}, \mathrm{CO}_{2}\right.$ of $5.3 \mathrm{kPa}$ or $40 \mathrm{mmHg}$ and $V^{\prime} \mathrm{E}$ of $\left.11.2 \mathrm{~L} \cdot \mathrm{min}^{-1}\right)$,
$V^{\prime} \mathrm{CO}_{2}$ is $412 \mathrm{~mL} \cdot \mathrm{min}^{-1}$, not the $450 \mathrm{~mL} \cdot \mathrm{min}^{-1}$ the authors state.

If medroxyprogesterone therapy was associated with a substantial increase in metabolic carbon dioxide production, then an increase in total ventilation would be necessary to prevent an increase in alveolar and arterial carbon dioxide tension production, in part defeating the purpose of the use of respiratory stimulants in this situation.

R.P. Cole

Dept of Medicine, Columbia University, New York, USA.

\section{References}

1. Wagenaar M, Je Vos P, Heijdra YF, Teppema LJ, Folgering HTM. Combined treatment with acetazolamide and medroxyprogesterone in chronic obstructive pulmonary disease patients. Eur Respir J 2002; 20: 1130-1137.

2. Staub NC. Basic Respiratory Physiology. New York, Churchill Livingston, 1991; pp. 52-53. 